\title{
BMJ Open Complexity in the new NHS: longitudinal case studies of CCGs in England
}

\author{
Katherine Checkland, Imelda McDermott, Anna Coleman, Neil Perkins
}

To cite: Checkland $\mathrm{K}$, McDermott I, Coleman A, et al. Complexity in the new NHS: longitudinal case studies of CCGs in England. BMJ Open 2016;6:e010199. doi:10.1136/bmjopen-2015010199

- Prepublication history for this paper is available online. To view these files please visit the journal online (http://dx.doi.org/10.1136/ bmjopen-2015-010199).

Received 7 October 2015 Revised 1 December 2015 Accepted 8 December 2015

Centre for Primary Care, University of Manchester, Manchester, UK

\section{Correspondence to} Professor Katherine Checkland:

Katherine.H.Checkland@ manchester.ac.uk

\section{ABSTRACT}

Objective: The reform in the English National Health Services (NHS) under the Health and Social Care Act 2012 is unlike previous NHS reorganisations. The establishment of clinical commissioning groups (CCGs) was intended to be 'bottom up' with no central blueprint. This paper sets out to offer evidence about how this process has played out in practice and examines the implications of the complexity and variation which emerged.

Design: Detailed case studies in CCGs across England, using interviews, observation and documentary analysis. Using realist framework, we unpacked the complexity of CCG structures.

Setting/participants: In phase 1 of the study (January 2011 to September 2012), we conducted 96 interviews, $439 \mathrm{~h}$ of observation in a wide variety of meetings, 2 online surveys and 38 follow-up telephone interviews. In phase 2 (April 2013 to March 2015), we conducted 42 interviews with general practitioners (GPs) and managers and observation of 48 different types of meetings.

Results: Our study has highlighted the complexity inherent in CCGs, arising out of the relatively permissive environment in which they developed. Not only are they very different from one another in size, but also in structure, functions between different bodies and the roles played by GPs.

Conclusions: The complexity and lack of uniformity of CCGs is important as it makes it difficult for those who must engage with CCGs to know who to approach at what level. This is of increasing importance as CCGs are moving towards greater integration across health and social care. Our study also suggests that there is little consensus as to what being a 'membership' organisation means and how it should operate. The lack of uniformity in CCG structure and lack of clarity over the meaning of 'membership' raises questions over accountability, which becomes of greater importance as CCG is taking over responsibility for primary care co-commissioning.

\section{INTRODUCTION}

The Health and Social Care Act (HSCA) $2012^{1}$ reorganised the English National Health Service (NHS), so comprehensively

\section{Strengths and limitations of this study}

- The study provides evidence about how clinical commissioning groups (CCGs) have decided to structure themselves to fulfil their statutory obligations.

- This is one of the first longitudinal approach to studying CCG development. So far data have been collected over a 3-4-year period, with further data collection ongoing at present. The study included detailed case studies across England, and thus provides a robust picture of CCGs.

- The triangulation of evidence from interviews, document analysis and observation enhances the trustworthiness of the findings.

- Although longitudinal in design, the study is taking place in a rapidly developing policy environment. Reports of results therefore represent a snap shot in time of a changing landscape.

- The research used case study methods. As with all such research, the generalisability of the findings lies in the extent to which these cases are typical of other such organisations, and on the extent to which the theoretical ideas addressed are applicable more widely.

that the changes were famously described by a senior NHS manager as requiring 'such a big change management you could probably see it from space'. ${ }^{2}$ The detail of the changes and the process by which they were enacted have been comprehensively described elsewhere ${ }^{3}$ this paper focuses on the introduction of clinical commissioning groups (CCGs), which replaced primary care trusts (PCTs), and uses evidence from an ongoing research programme to explore the complexities of the new system.

CCGs were established as statutory bodies responsible for commissioning a full range of healthcare services from a range of providers in England. Established in shadow form from late 2011, they went 'live' in April 2013. CCGs were intended to be 'clinically led;' ${ }^{4}$ in practice, while other clinicians such as nurses 
and hospital consultants have some role to play, it is general practitioners (GPs, family doctors) who take the lead. Unlike previous NHS reorganisations, the development of CCGs was intended from the beginning to be 'bottom up'. No central blueprint was provided, and potential CCGs were encouraged to come together as 'Pathfinders' to test out configurations and approaches. PCTs were encouraged to support and enable the process:

PCTs should provide support for this process and empower [CCGs] to take on new responsibilities quickly when they are ready to do so, but it is important that solutions develop from the bottom up and are not imposed from above. GP commissioners should have the freedom to arrange themselves as they see fit to best meet the needs of their local populations'. (Ref. 5, p.5)

No ideal size was suggested, and geographical coverage was left for local groups to decide. However, it was specified that they should: cover a defined geographical area; only cross local authority (LA) boundaries where there was clear justification to do so; include a hospital consultant and a senior nurse in their senior team; have a constitution, setting out their internal structures and governance arrangements; and have an accountable officer, taking statutory responsibility for the work of the CCG. Most importantly, CCGs were to be established as 'membership organisations', with GP practices as members, collectively making decisions about how the CCG should be set up and function. ${ }^{67}$

This paper offers evidence about how this process played out in practice, and examines the implications of the complexity and variation which emerged.

\section{HISTORY: THE STRUCTURE OF COMMISSIONING ORGANISATIONS IN THE NHS}

Prior to 1990, the focus in the NHS was on strategic planning. While exact configurations of responsible authorities changed over time, with the successive creation and abolition of different organisations such as District/Regional Health Authorities, the focus was on 'authorities', which carried responsibility for planning services to meet the needs of a geographical population. ${ }^{8}$ Leadership was in the hands of a 'triumvirate': senior administrator, lead medical officer and lead nurse. The Griffiths report in $1983^{9}{ }^{10}$ advocated their replacement with a single general manager, who would take overall responsibility for the work of the authority. The next significant change occurred in 1991 with a split between the 'purchasing' of healthcare and its provision, with newly established health authorities responsible for purchasing care from quasi-independent 'NHS Trusts'. ${ }^{8}{ }^{11}$ It was argued that 'purchaser-provider split' would improve efficiency and effectiveness. NHS Trusts were established with governance arrangements which mirrored private sector companies, with a Board containing executive directors (ED) and non-executive directors (NED). NED formed a majority, with ED responsible for the operational management. Following New Labour's NHS reforms, purchasing organisations (rebadged as 'commissioners') were also established on this model, with PCTs led by a Board of ED and NED $^{12} 13$ established from 2001.

PCTs were initially established covering populations of approximately 100000 , but subsequent mergers increased this to approximately $300000 .{ }^{14}$ While variation existed between PCTs, there was a general uniformity in their overarching structures and functions. All had a board of ED and NED, with the latter in a majority, and all had an advisory Professional Executive Committee (PEC), bringing together doctors, nurses and allied health professionals to provide clinical advice to the board. The Board was led by a lay Chair, and the senior manager was styled as chief executive, mirroring private sector board structures. Beneath the Board there were directorates, each headed by a senior board executive. Job titles varied, but most included a Director of Finance, a Director of Commissioning, a Medical Director, a Director of Nursing and Director of Public Health. Sub-board level committees carried responsibility for programmes and areas of work, such as urgent care or cardiovascular disease. ${ }^{15}$

The guidance for CCGs, by contrast, allowed them to establish themselves as they saw fit within some broad guidelines. ${ }^{7} 16$ As 'membership organisations', the analogy with private sector companies was lost, with a 'Governing Body' (GB) replacing a Board. The GB was not required to have a lay or non-executive majority, and while CCGs were encouraged to appoint a senior manager, the use of the term 'Chief Executive' was discouraged. Overall leadership of CCGs was to be shared between an accountable officer (who could be a GP or a manager) and Chair (who could be clinical or nonclinical), supported by a chief finance officer and, if the accountable officer was a clinician, another senior manager, styled as 'Chief Operating Officer'. CCGs were encouraged to involve their member practices in appointments to the GB, with many holding elections. However, late in the process, some formal requirements were introduced for the appointment of senior leaders, with CCGs required to submit their choices for the senior roles for ratification to NHS England. ${ }^{17}$ This guidance also stipulated that CCGs should have a quality committee and an audit and remuneration committee, and that GBs should include lay membership, along with a hospital consultant and a nurse from outside the geographical area. ${ }^{16}$ Detailed structures were left for the CCG to decide, along with such things as the numbers of GPs on the GB, GB roles, procedures members' involvement and the establishment of working groups.

Understanding how CCGs are constituted and how they function are thus empirical questions, requiring research and exploration. They are important, because judging the factors affecting the success and impact of CCGs will require a clear understanding of their internal 
Table 1 Site characteristics

\begin{tabular}{llllr}
\hline Sites & $\begin{array}{l}\text { Size } \\
\text { (quintile) }\end{array}$ & $\begin{array}{l}\text { Sociodemographic } \\
\text { profile and area }\end{array}$ & Major providers & $\begin{array}{c}\text { Local } \\
\text { authorities }\end{array}$ \\
\hline Site 1 & 3 & No & Mixed & 1 \\
Site 2 & 5 & Yes & Relatively homogeneous, pockets of deprivation & $>1$ \\
Site 3 & 5 & No & Relatively homogeneous, affluent, pockets of deprivation & $>1$ \\
Site 4 & 2 & Yes & Relatively homogeneous, deprived & $>1$ \\
Site 5 & 3 & No & Relatively homogeneous, deprived & 1 \\
Site 6 & 2 & No & Relatively homogeneous, affluent & $>1$ \\
Site 7 & 4 & No & Mixed & 1 \\
Site 8 & 4 & No & Mixed & 1 \\
\hline
\end{tabular}

structures and procedures. Making judgements about the value of the role of clinicians requires an understanding of what GPs do and how they fit into the wider organisation. This paper reports the findings from a research programme following CCGs from their early establishment. It provides the first evidence about how CCGs have decided to structure themselves to fulfil their statutory obligations, addressing the following research questions:

- How did CCGs approach the task of setting themselves up, and what did they take into account in this process?

- How are CCGs structured, and what roles have GPs adopted?

\section{METHODS}

This paper reports on phases 1 and 2 of an ongoing research programme, exploring the development and functions of CCGs in England. Phase 1 (January 2011 to September 2012) included two online surveys (response rates $104 / 253=41 \%$ and $118 / 209=56 \%$ ), eight qualitative case studies, including interviews with a wide variety of respondents $(n=96)$, meeting observation $(439 \mathrm{~h})$, and follow-up telephone interviews $(n=38)$ with a random sample of CCG leaders. ${ }^{18}$ Phase 2 (April 2013 to March 2015) included interviews with senior CCG staff (focusing on GPs and managers) in the seven sites $(n=42)$, followed by observation of a wide variety of meetings $(n=48)$ in four sites. ${ }^{19}$ Case study sites were selected purposively according to size, sociodemographic profile and deprivation, complexity (how many major providers they have and whether or not they cross LA boundaries), and how close the CCG is to some previous administrative grouping. Data collection is summarised in tables 1 and 2.

In terms of analysis, in phase 1, data were analysed thematically focusing on the decisions being made by CCGs as they set themselves up. One of the issues highlighted was the perception of GP 'added value' in both commissioning and contracting. In phase 2, we set out to explore this 'added value'. We asked staff to explain how they felt GPs were contributing to CCG's work. ${ }^{20}$ We followed up these claims in four of the eight sites (sites 1, 5, 7 and 8) by observing GPs' work in CCG meetings. Using a realist approach, ${ }^{21}$ we identified the contexts in which GPs contribute most effectively to commissioning and the mechanisms underlying that contribution. During this phase, the complexity of CCG structures became increasingly apparent. This complexity made it very difficult for the research team to make comparisons between the different sites, as it was unclear how the differently named and constituted GBs, committees, etc, related to one another in both structure and function. This paper seeks to explore this complexity.

\section{RESULTS}

In this section, evidence from both phases of the research is reported together.

Table 2 Phases 1 and 2 interview respondents by type

\begin{tabular}{|c|c|c|c|}
\hline \multirow[b]{2}{*}{ Type of respondents } & \multicolumn{2}{|l|}{ Phase 1} & \multirow[b]{2}{*}{$\begin{array}{l}\text { Phase } 2 \\
\text { Number of interviews }\end{array}$} \\
\hline & Number interviewed & $\begin{array}{l}\text { Number of interviews } \\
\text { (some interviewed twice) }\end{array}$ & \\
\hline Manager (NHS) & 47 & 49 & 6 \\
\hline GPs & 33 & 36 & 35 \\
\hline Lay member & 5 & 5 & 0 \\
\hline Practice manager & 3 & 3 & 0 \\
\hline Nurse (clinical lead) & 1 & 1 & 1 \\
\hline Others (eg, trust manager) & 1 & 1 & 0 \\
\hline Local Authority representatives & 1 & 1 & 0 \\
\hline Total & 91 & 96 & 42 \\
\hline
\end{tabular}




\section{CCG size and configuration}

CCGs were given no guidance about the size of population that they should cover. Early in the process a 'running costs calculation tool ${ }^{\text {,22 }}$ was provided, which allowed CCGs to explore the running costs they would receive for different populations. This led some to decide that their proposed CCG was too small to be viable:

[NurseID252] said that there was difficulty in being a CCG on their own-'we can't afford it'. They could share management, but not be a CCG alone. On Tuesday it felt like a 'fait accompli'.

[PMID251] said that they had looked at the running cost models provided by the $\mathrm{DH}$ on the 'ready reckoner'. Current guidance is that looking at the running cost estimates available (£25/head) they could not afford for [three local CCGs] to run their own statutory boards and to buy in the appropriate amount of commissioning support. BUT the actual figures are not out yet. If there were a smaller, slimmer board he feels that they could manage it. [neighbouring CCG] take a different view. They do not want to be standalone-they want to merge, as they feel that the available running costs are not enough... [extract from pre-authorisation CCG meeting M2]

Other CCGs decided that they wished to stay small, but would reduce costs by sharing posts. Over time, mergers took place, with an initial 259 'Pathfinders' reducing to 211 CCGs after authorisation. Our survey showed a wide variation in CCGs' size, with CCG population coverage ranging from 90000 to 855000 and number of practices forming the membership varying from 10 to 110. In 2013, the Office of National Statistics released CCG population figures based on the national census ranging from 61600 in NHS Corby to 863400 in NHS North, East, West Devon (http://www.ons.gov.uk/ ons/rel/sape/clinical-commissioning-group-populationestimates/mid-2011-census-based-/stb—clinical-commissioning-groups-mid-2011.html).

\section{GB membership}

Our study found considerable variation in the proposed membership of GBs as CCGs prepared for authorisation. The size of GBs was variable and appeared to have no clear relationship with CCG size (figure 1).

Some CCGs reported a GB with more than 25 members. Background of GB members was also very variable. In the online survey, we asked CCGs to indicate whether or not they had particular types of professional/manager on their GB (figure 2).

Thus, $33.0 \%$ of CCGs reported a social services representative on their GB, $26.8 \%$ reported a salaried GP and $61.6 \%$ reported an ex-PCT NED. These figures do not distinguish between voting and non-voting members of GBs, and it is quite likely that since authorisation GB membership has developed further. However, these figures illustrate clearly the variation and complexity
Size of CCG Governing Body from 2nd web survey

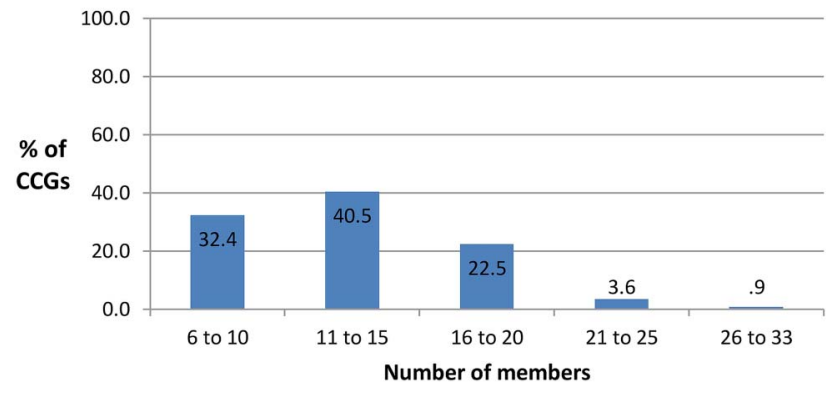

Figure 1 Size of clinical commissioning group (CCG) Governing Body from second web survey.

present in CCGs. We calculated the percentage representation of GPs on GBs, and this again showed considerable variation (figure 3). Gender breakdown was also variable, with female GPs only constituting $20 \%$ of GB members.

\section{Developing complexity}

Our study explored what exactly GPs were doing in CCGs to understand their roles and the 'added value' that they bring. We found that the complexity of CCG structures makes it difficult to make unambiguous claims about the extent to which GPs could or should be involved. This is important because GP time is expensive, in terms of the money paid to them and to their practices in order to backfill their time, and in the softer costs associated with losing experienced GPs and relying on locums. GPs roles were many and various. In one CCG, they set up a clinical team whose remit was limited to development and implementation of commissioning plans and pathways. In another CCG, they decided that their clinical team should also deal with strategic and operational issues. Other CCGs decided that the roles adopted by GPs (and clinicians) should be more specific in terms of overseeing commissioning activities, determining commissioning strategy and priorities, and ensuring localities commissioning decisions are aligned to commissioning plan. Overall, our study suggests that there is no 'typical' GP role, and that the roles adopted by GPs are determined by a complex mix of factors such as: individual preferences and previous experience; the structures adopted by the CCG; and the preferences and attitudes of senior managers within the CCG.

It also proved very difficult to clarify which bodies within our study CCGs did what. GB membership varied, some having a GP majority while others only had a small number of GP representatives. Some had GPs as Accountable Officers, while others had managers, and some were chaired by GPs, while others by a lay member. The approach taken to their role was also different. In some CCGs, the GB took a role which was somewhat similar to that of PCT Boards, receiving reports from other committees and 'signing off' decisions. In another, the GB was also an operational group, 
Figure 2 Percentage of CCGs with a particular member on GB (CCG, clinical commissioning group; GB, governing body; GP, general practitioner; NHS, National Health Service; PCT, primary care trust).
Percent of CCGs with a particular member on GB

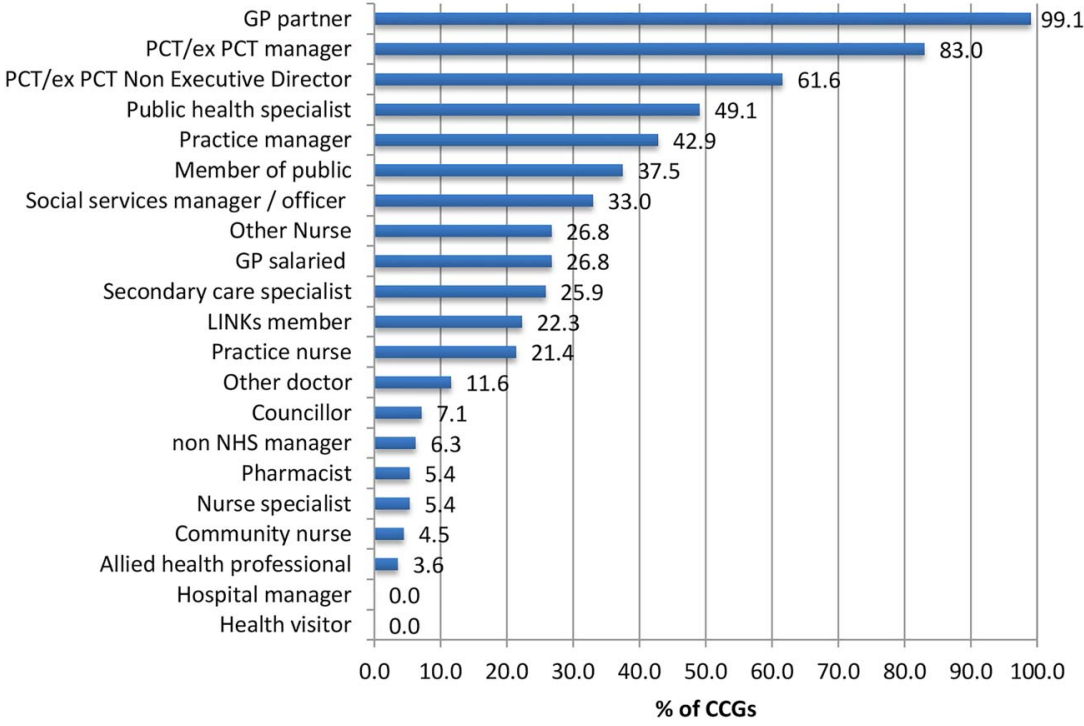

undertaking substantive discussions and making operational decisions. GBs are required to meet in public; however, how this should be operationalised was not stipulated, and our case study CCGs interpreted this rather differently, with one meeting every month in public, two meeting every 3 months and one only doing so three times a year. PCT boards, by contrast, always met in public for at least part of every meeting.

In addition to the variability in the remit and membership of the GB, the way the 'operational' or 'doing' bodies are structured in our case study sites also varies. All four CCGs had some sort of executive or operational group which sat beneath the GB, but these varied greatly in their membership, role and name; some referred to an 'Executive' while others called it a 'Commissioning Committee'. In one study CCG there was a separate clinical and managerial executive, while in the others the executive combined managerial and clinical members. In one CCG the 'Executive' contained a majority of GPs, while in others it was managerially dominated or had a separate managerial group which met in parallel to the Executive. The remit of these groups were difficult to fully understand, with existing 'terms of reference' written at a high level of abstraction

GPs as a proportion of total CCG Governing Body members

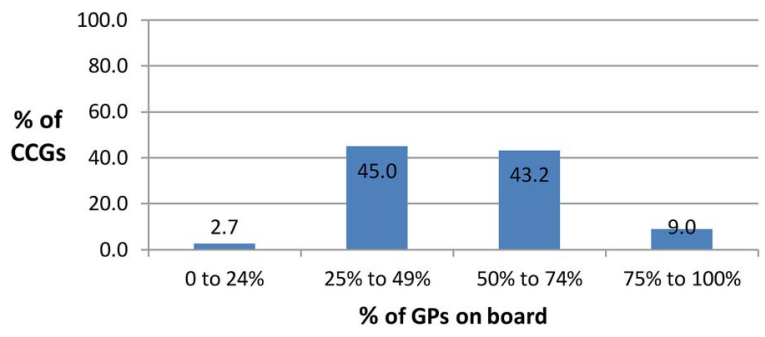

Figure 3 Percentage number of general practitioners (GPs) as a proportion of total clinical commissioning group (CCG) Governing Body members. and including such things as 'strategy and planning' and 'overseeing commissioning'. Hence, it was difficult articulate exactly what these groups do, or generate meaningful comparisons between them. It is questionable whether the CCG themselves are aware of how complex their internal structures are and how different they are from each other.

We also found variability in the remit and membership of the working committees below the GB. All have an Audit Committee and a Remuneration Committee, as required by statute. They also must have a 'Quality Committee', but we found their remit vary considerably. Some encompass finance and contract monitoring functions, while others have separate committees for these functions. Some focus on clinical governance issues, while others encompassed performance against contracts and finance. CCGs also have a range of membership groups, such as geographically based locality groups, but we found little consistency in what these groups do. Some have formal delegation of some aspects of commissioning activity, with associated delegated budgets, while others function more for information collection and dissemination. In addition, some CCGs have regular (often quarterly or biannual) meetings of the entire membership where in one CCG this was seen as having an important role in strategy development, while others it was for information dissemination and education.

\section{GP roles}

GPs play a wide variety of roles in CCGs. Unlike PCTs, where GP involvement was largely limited to a small number of people with formal roles, such as PEC Chair, GPs are involved at all levels in CCGs. In our online survey, $28 \%$ of 110 CCGs reported a GP as Accountable Officer, while $90 \%$ reported a GP Chair. In one of our study CCGs, each committee was established with a dual leadership of a GP alongside a senior manager, working together to lead the work of the group. In some CCGs, 
each locality has a lead GP, and these GPs sit on the GB; in others, GP involvement at GB level is more limited. We found that, initially at least, GPs with formal roles tended to be those who had had lead roles in the past, such as PEC Chair or practice-based commissioning lead. In the 8 CCGs involved in the first phase of the research, there were 57 GPs involved at GB level; of these, 50 had held previous roles in PCTs or PBC. They were acutely aware of the need to develop succession plans, with some actively recruiting new GPs to take on formal roles. There was concern about the longer term viability of GP involvement and over-reliance on a few individuals:

I'm still unsure of the long term involvement of GPs in this whole thing, because I do feel, you know, I think GPs, you know, the issue around GPs, you have an initial enthusiasm from the GPs. You've seen our GPs round the table; I don't see any succession planning, or that much succession planning-I don't blame anyone for it-but if [the] Chair, tomorrow said, 'I'm bored, I've had enough of this', I haven't got a clue who would step into that role. And if at the end of say two years, [GPID102] said, 'my practice needs me back', or [GPID104], I don't know who would do it, and I really think that's a problem with the whole system [ManagerID116]

All CCGs in our case studies expressed difficulty in enthusing and engaging new GP leaders which is crucial to the long-term progression of CCGs. There was one case study site which was successful in bringing forward a significant number of new GP leaders. They did this by engaging a wider group of GPs in a forum which focused specifically on local clinical issues. This was successfully used as a recruiting ground for new GP members. Some CCGs planned to seek re-election on a regular basis (eg, every 3 years) or on a rolling basis.

\section{Effect of CCG size}

Some of the variation and complexity that we have highlighted can be in part explained as a reasonable response to the variation in size of CCGs. A large CCG covering a population of more than 500000 people will need a different structure than one with a population of 80 000. However, we also found that GB size was not clearly related to CCG size, with some of the larger GBs occurring in smaller CCGs. This seemed, in part, to be designed to increase representation with, for example, some small CCGs having a member of every practice on their GB. Similarly, while larger CCGs will need strong locality structures to ensure they remain close to the needs of their populations, we found that some smaller CCGs also maintain extensive locality structures.

\section{DISCUSSION}

Our study has highlighted the complexity inherent in CCGs, arising out of the relatively permissive environment in which they developed. They are not only different in size, but also in structure, how functions are distributed between different bodies and in the roles GPs played. The organisational studies literature historically focused to a significant degree on the relationship between form and function. ${ }^{23}{ }^{24}$ It was assumed that particular organisational forms could be optimised to deliver particular functions, and large research programmes developed which sought to catalogue form and measure the resulting functionality. ${ }^{25}$ Recently, focus has moved towards fluidity and adaptability of form, with the argument made that current economic and market conditions require networked organisations able to adapt. ${ }^{26}$ From this perspective, 'function' comes first, with the 'best' form defined as that which can deliver the functions required.

Viewed through this lens, the establishment of PCTs and other NHS Trusts with organisational structures mirroring private sector organisations implies an approach focused on governance and oversight. Managerial 'doers' would be overseen by a majority of quasi-independent NED, and managers lower down the hierarchy would have relatively little autonomy, with all significant decisions requiring board 'sign off'. This particular organisational form is perfectly adapted to strong topdown direction, with the clinical voice (represented by the PEC) possibly muted by its position outside the mainstream of the hierarchy. The laissez faire approach to organisational form embodied in the HSCA 2012, by contrast, has generated GBs with much less clear form or function. Structures also vary significantly between CCGs, with different names used for roles and committees, and with different approaches to delegation of authority. This lack of formal structure makes understanding internal accountability between the different levels within CCGs difficult. With a more fragmented system overall, this could make coordination and working together more difficult due to differences in terms of role, function and structure. It remains unclear how far these very different structures will be reflected in different approaches to commissioning. Some CCGs have taken a relatively radical approach with, for example, Kernow CCG in Cornwall currently putting their community services out to tender, with private companies apparently bidding for the contract (http:// www.thecommissioningreview.com/article/kernow-ccgpressured-stop-hospital-privatisation). Others have continued to commission and contract with their historical providers in a relatively unchanged way. Further research could usefully explore such decisions, seeking to relate GB structure and representation to the approach taken to potentially contentious and contested decisions.

The strength of this study is in its longitudinal approach to studying CCG development. So far data have been collected over a 3-4-year period, with further data collection ongoing at present. This gives a valuable insight into the way that new organisations develop in an environment with little overt direction. This longitudinal approach in a rapidly developing policy environment 
also brings with it difficulties, in that any account of what has been seen is open to the criticism that things have already moved on, and that the issues raised have been dealt with. We have tried to mitigate this danger by presenting some of the changes seen over time, but it is inevitable that some readers-particularly those with first-hand knowledge of CCGs-will find some things reported here that they do not currently recognise.

There is as yet little published evidence about CCGs and their development. The most significant work comes from the Kings Fund/Nuffield Trust, who have been carrying out a longitudinal study of CCG development over a similar timescale to the study reported here, focusing on the role of CCGs in supporting quality improvement in primary care. ${ }^{27}$ They report that less than half of GP leaders in their study felt they had enough time and support, and their study mirrored our finding that there are significant concerns about succession, with little confidence that a new generation of GP CCG leaders could be found. They also found that CCGs were beginning to change their governance arrangements, with some scaling back their GP representation. Recently, Storey et al report on case studies in six CCGs, and highlight diversity in ambition and scope of activity of CCGs. They point to relatively limited ambitions in some CCGs, and report the role of senior managers in encouraging or constraining such ambition, and conclude that there is a lack of good evidence for widespread larger scale change initiated by CCGs. ${ }^{28}$ Our evidence provides important context for these findings, and suggests some important underlying mechanisms which may underpin these findings, in particular the variation in operational and strategic decision-making arrangements in CCGs, and the variation in the scope of roles played by GPs.

It might seem that the issues highlighted in this study and in the Kings Fund/Nuffield work are somewhat esoteric and of little general interest. However, it is our contention that the complexity and lack of uniformity of CCGs is important for a number of reasons. First, there is the purely practical question that it is very difficult for an outsider to have a clear understanding of who does what within a CCG. Even after attending meetings at multiple levels within our study CCGs, the research team remained unclear about where different responsibilities lay within the different structures, and how they could be compared. This complexity makes it difficult for those who must engage with CCGs to know a priori who to approach at what level, which is of increasing importance as we move towards greater integration across health and social care. ${ }^{29}$ Ongoing research in this longitudinal study reinforces the importance of this finding with many respondents in the later stages of the study lamenting the loss of clear line of communication and highlighting the valuable role of personal relationships in enabling communication in a complex landscape. Second, the loss of the non-executive majority is something which has been little commented on. The assumption within the HSCA is that the 'membership' of the
CCG would play the oversight role, previously played by non-executives, of making sure that voices outside the managerial structure would be heard. Our research suggests that there is little consensus as to what this means or how it should operate, and the Kings Fund/Nuffield study concurs, finding that CCGs were struggling over how best to engage their membership. ${ }^{27}$ As CCGs start to take over responsibility for primary care co-commissioning, ${ }^{30}$ the need for a strong external voice becomes even more important. Guidance relating to co-commissioning suggests the setting up of a new committee with a non-GP majority in order to guard against conflicts of interest. However, if this committee remains subordinate to the GB (as guidance suggests ${ }^{31}$ ), then any decision it makes can potentially be overturned. Third, the lack of clarity over the meaning of CCG 'membership' means that there is a lack of clarity over accountability. While each CCG has a constitution, these do not, in general, set out clearly the circumstances in which CCG members could remove or sanction their leaders. This becomes of greater importance as CCGs take over responsibility for commissioning primary care services. It is entirely possible that CCG leaders may make decisions about the provision of primary care services with which members (providing those services) disagree. Thus, for example, it is currently a Department of Health priority to move towards the provision of routine primary care services 7 days a week. ${ }^{32}$ Such a change in service may well not be popular among CCG members; how any such disagreements might be managed remains unclear at present.

The role of CCGs has been changing and developing since they were first introduced, and this is continuing at a rapid pace. With current policy requiring CCGs to take over responsibility for commissioning primary care services, support the development of new models of service provision and work more closely with LAs, other providers (eg, voluntary sector) and other local bodies (eg, Health and Wellbeing Boards), the issues we have highlighted will become increasingly important. LAs with a number of CCGs in their area will need to be flexible in their approach, getting to know the CCGs individually and tailoring their approach to the particular structures within each CCG. Providers similarly are faced with a complex landscape to negotiate, and it is likely that in these circumstances individual personal relationships will be increasingly important, further reducing transparency. In primary care provision, GP Provider Federations are beginning to develop. These were initially set up by GPs not directly involved in commissioning, in an attempt to ring fence the funding for enhanced services. ${ }^{33}$ However, many CCGs are now supporting their development, and the membership of GP Federations is often identical to the membership of the local CCG, albeit with different leaders. Conflicts of interest and the role members play in the CCG will be of even greater importance as these develop further. Issues of governance and accountability will also be important as CCG roles expand. Foundation Trusts were an attempt to bring in a new organisational form which shifted 
accountability relationships and improved responsiveness to local people. In practice, research has shown that this model has delivered little in the way of local accountability. ${ }^{34}$ The GB model adopted by CCGs is supposed to embody an ideal of accountability to members; it remains to be seen if this remains the most effective governance model as the commissioning landscape changes.

Acknowledgements The study formed part of the programme of the Policy Research Unit on Commissioning and the Healthcare System. The authors are grateful to their participants who were very generous in allowing access to their organisations at a time of considerable turmoil and change. The authors are also grateful to Dr Dorota Osipovič, Dr Christina Petsoulas, Dr Julia Segar, Ms Rosalind Miller and Dr Andrew Wallace who undertook the fieldwork and contributed to the analysis and final report. Employees of the Department of Health were members of an advisory group who supported the conduct of the research, and commented on an initial draft of the study final report.

Contributors KC was principal investigator for the project, produced the first draft and finalised the paper. KC, AC and IM conceived and designed the project, were involved in data collection and analysis and made substantial comments on all versions of the paper. NP was involved in data collection and analysis and made substantial comments on all versions of the paper.

Funding The Policy Research Unit in Commissioning and the Healthcare System (PRUComm) is funded by the Department of Health Policy Research Programme.

Disclaimer The views expressed are those of the authors, and not the Department of Health.

Competing interests None declared.

Ethics approval The study received ethical approval from National Research Ethics Service North West ref 0375 and the University of Manchester Research Ethics Committee.

Provenance and peer review Not commissioned; externally peer reviewed.

Data sharing statement No additional data are available.

Open Access This is an Open Access article distributed in accordance with the Creative Commons Attribution Non Commercial (CC BY-NC 4.0) license, which permits others to distribute, remix, adapt, build upon this work noncommercially, and license their derivative works on different terms, provided the original work is properly cited and the use is non-commercial. See: http:// creativecommons.org/licenses/by-nc/4.0/

\section{REFERENCES}

1. Health and Social Care Act. London Stationery Office. Department of Health. 2012.

2. Gulliford M, Figueroa-Munoz J, Morgan M, et al. What does 'access to health care' mean? J Health Serv Res Policy 2002;7:186-8.

3. Timmins N. Never again? The story of the Health and Social Care Act 2012. A study in coalition government and policy making. London: The King's Fund, 2012.

4. Department of Health. Equity and excellence: liberating the NHS. London: The Stationary Office, 2010.

5. Nicholson D. Letter to all Chief Executives and arm's length bodies. Equity and Excellence: Liberating the NHS - Managing the transition. (Gateway ref 14795). Department of Health. 2010. https://www.gov. uk/government/uploads/system/uploads/attachment_data/file/ 216022/dh_119331.pdf

6. Department of Health. The functions of GP Commissioning Consortia: A working document (Gateway ref 154722). 2011.
7. NHS Commissioning Board. Towards establishment: creating responsive and accountable Clinical Commissioning Groups. 2012

8. Klein R. The new politics of the NHS: from creation to reinvention. London: Radcliffe Publishing Ltd, 2006.

9. Griffiths R. NHS Management Enquiry. 1983.

10. Harrison S, Hunter D, Marnoch G, et al. Just managing: power and culture in the National Health Service. Basingstoke: Macmillan, 1992.

11. Department of Health. Working for patients. London: The Stationary Office, 1989.

12. Department of Health. The new NHS: modern, dependable. London: The Stationary Office, 1997.

13. Department of Health. Primary care trusts: establishing better services. London: The Stationary Office, 1999

14. Department of Health. Creating a patient-led NHS-delivering the NHS improvement plan. The Stationary Office, 2005.

15. Checkland K, Snow S, McDermott I, et al. Management practice in Primary Care Trusts: the role of middle managers. NIHR Service Delivery and Organisation programme, 2011

16. NHS Commissioning Board. Clinical commissioning group governing body members: role outlines, attributes and skills. October 2012

17. NHS Commissioning Board. Clinical Commissioning Groups HR Guide. May 2012.

18. Checkland K, Coleman A, Segar J, et al. Exploring the early workings of emerging Clinical Commissioning Groups: final report. London: Policy Research Unit in Commissioning and the Healthcare System (PRUComm), 2012. http://blogs.Ishtm.ac.uk/prucomm/files/ 2012/11/Pathfinder-project-final-report-revised-v10-combined-postpeer-review-FINAL-correct-date_titles.pdf

19. McDermott I, Coleman A, Perkins N, et al. Exploring the GP 'added value' in commissioning: What works, in what circumstances, and how? London: Policy Research Unit in Commissioning and the Healthcare System (PRUComm), 2014. http://blogs.Ishtm.ac.uk/ prucomm/files/2015/10/CCG2-final-report-post-review-v3-final.pdf

20. Perkins $\mathrm{N}$, Coleman $\mathrm{A}$, Wright $\mathrm{M}$, et al. Involving GPs in commissioning: what 'added value' do they think they bring to Clinical Commissioning Groups? Br J Gen Pract 2014;64:e728-e34. http://dx.doi.org/10.3399/bjgp13X671597

21. Pawson R. The science of evaluation: a realist manifesto. London: Sage, 2013.

22. Department of Health. Commissioning Support: Clinical Commissioning Group Running Costs Tool. A 'Ready Reckoner'. (Gateway ref 16585). 2011.

23. Chandler AD. Managerial hierarchies. In: Pugh DS, ed. Organization theory: selected writings. 3rd edn. London: Penguin Books, 1990;95-123.

24. Reed M. The sociology of organizations: themes, perspectives and prospects. New York: Harvester Wheatsheaf, 1992.

25. Pugh DS, Hickson DJ. Writers on organizations. 5th edn. London: Penguin, 1996.

26. Barlow J, Röber M. Steering not rowing: co-ordination and control in the management of public services in Britain and Germany. Int $J$ Public Sector Manag 1996;9:73-89.

27. Holder $\mathrm{H}$, Robertson R, Ross $\mathrm{S}$, et al. Risk or reward? The changing role of CCGs in general practice. London: King's Fund/Nuffield Trust, 2015.

28. Storey J, Holti R, Hartley J, et al. Clinical leadership through commissioning: Does it work in practice? Health Serv Manage Res 2015;28:1-8.

29. NHS England. Five year forward view. NHS England, 2014

30. NHS England. Next steps towards primary care co-commissioning. NHS England, 2014.

31. Mays N, Goodwin N, Bevan G, et al. What is total purchasing? BMJ 1997;315:652-5.

32. NHS England. Everybody counts: planning for patients 2013/14. NHS England, 2013.

33. Charlton R. GP commissioning: the first year. Clin Med 2014; 14:221-2.

34. Allen P, Townsend J, Dempster P, et al. Organizational form as a mechanism to involve staff, public and users in public services: a study of the governance of NHS Foundation Trusts. Soc Policy Adm 2011;46:239-57. 